\title{
Targeted inactivation of hepatic Abca1 causes profound hypoalphalipoproteinemia and kidney hypercatabolism of apoA-I
}

\author{
Jenelle M. Timmins, ${ }^{1}$ Ji-Young Lee, ${ }^{1}$ Elena Boudyguina, ${ }^{1}$ Kimberly D. Kluckman, ${ }^{2}$ Liam R. Brunham, ${ }^{3}$ \\ Anny Mulya, ${ }^{1}$ Abraham K. Gebre, ${ }^{1}$ Jonathan M. Coutinho, ${ }^{3}$ Perry L. Colvin, ${ }^{4}$ Thomas L. Smith, ${ }^{5}$ \\ Michael R. Hayden, ${ }^{3}$ Nobuyo Maeda, ${ }^{2}$ and John S. Parks ${ }^{1}$

\begin{abstract}
'Department of Pathology, Wake Forest University School of Medicine, Winston-Salem, North Carolina, USA. ${ }^{2}$ Department of Pathology University of British Columbia, Vancouver, British Columbia, Canada. ${ }^{4}$ Division of Gerontology, University of Maryland School of Medicine, Baltimore, Maryland, USA. ${ }^{5}$ Orthopedic Surgery, Wake Forest University School of Medicine, Winston-Salem, North Carolina, USA
\end{abstract} \\ and Laboratory Medicine, University of North Carolina, Chapel Hill, North Carolina, USA. ${ }^{3}$ Centre for Molecular Medicine and Therapeutics,
}

\begin{abstract}
Patients with Tangier disease exhibit extremely low plasma HDL concentrations resulting from mutations in the ATP-binding cassette, sub-family A, member 1 (ABCA1) protein. ABCA1 controls the rate-limiting step in HDL particle assembly by mediating efflux of cholesterol and phospholipid from cells to lipid-free apoA-I, which forms nascent HDL particles. ABCA1 is widely expressed; however, the specific tissues involved in HDL biogenesis are unknown. To determine the role of the liver in HDL biogenesis, we generated mice with targeted deletion of the second nucleotide-binding domain of $A b c a 1$ in liver only $\left(A b c a 1^{-L / L}\right)$. $A b c a 1^{-L / L}$ mice had total plasma and HDL cholesterol concentrations that were $19 \%$ and $17 \%$ those of wild-type littermates, respectively. In vivo catabolism of HDL apoA-I from wild-type mice or human lipid-free apoA-I was 2-fold higher in $A b c a 1^{-L /-L}$ mice compared with controls due to a 2 -fold increase in the catabolism of apoA-I by the kidney, with no change in liver catabolism. We conclude that in chow-fed mice, the liver is the single most important source of plasma HDL. Furthermore, hepatic, but not extrahepatic, Abca1 is critical in maintaining the circulation of mature HDL particles by direct lipidation of hepatic lipid-poor apoA-I, slowing its catabolism by the kidney and prolonging its plasma residence time.
\end{abstract}

\section{Introduction}

HDL cholesterol (HDL-C) concentration is inversely proportional to cardiovascular disease risk (1). This relationship is thought to be mediated by the ability of HDL to transport excess cholesterol from peripheral tissues back to the liver for excretion in a process known as reverse cholesterol transport (RCT) (2). An understanding of the molecular events in HDL formation is necessary for the development of therapeutic strategies to raise HDL-C levels and protect against atherosclerosis.

HDL biogenesis is poorly understood. Initially, HDL particle formation was thought to occur inside the cell, by a process similar to that for the formation of VLDL and LDL particles (3). However, the assembly of free cholesterol (FC) and phospholipid (PL) with lipid-free apoA-I to form nascent HDL particles is now thought to occur extracellularly (3-5). Fibroblasts from patients with Tangier disease are unable to assemble PL and FC with apoA-I (6), and these patients are characterized by a near absence of plasma HDL and the accumulation of cholesterol esters in tissues enriched with macrophages (7). The discovery that mutations in the (ATP-binding cassette, sub-family A, member 1) ABCA1 gene cause Tangier disease

Nonstandard abbreviations used: ABCA1, ATP-binding cassette, sub-family A member 1; FC, free cholesterol; FCR, fractional catabolic rate; FPLC, fast performance lipid chromatography; HDL-C, HDL cholesterol; HL, hepatic lipase; LCAT, lecithin cholesterol acyltransferase; LXR, liver X receptor; PL, phospholipid; PLTP, PL transfer protein; RCT, reverse cholesterol transport; SR-BI, scavenger receptor class B, type I; TC, tyramine cellobiose; TG, triglyceride; WHAM, Wisconsin hypoalpha mutant. Conflict of interest: The authors have declared that no conflict of interest exists.

Citation for this article: J. Clin. Invest. 115:1333-1342 (2005).

doi:10.1172/JCI200523915. and familial hypoalphalipoproteinemia has clearly established ABCA1 as the key protein responsible for the assembly of FC and PL with lipid-free apoA-I and a critical molecule regulating an initial step in RCT and nascent HDL particle assembly (8-10).

According to the traditional model of RCT, HDL-C originates from peripheral tissues and is subsequently transferred to the liver (2). However, recent studies have challenged this model based on the finding of overexpression of ABCA1 by the liver, which raised plasma HDL concentrations and suggested that significant HDL particle assembly occurred at the hepatocyte surface (11-13). In addition, bone marrow transplantation studies revealed that the macrophage is not a significant source of plasma HDL-C (14). Furthermore, only 2 tissues, the liver and intestine, are quantitatively important in the synthesis and secretion of apoA-I (15). These findings suggest that the liver may be a significant source of HDL particles. However, the contribution of the liver to HDL biogenesis is unknown.

To definitively determine the role of hepatic Abca1 in HDL particle formation and catabolism, we developed liver-specific Abca1-knockout mice $\left(A b c a 1^{-L / L}\right)$ by gene targeting. Our results demonstrate that hepatic Abca1 is essential for the lipidation of nascent apoA-I and the maintenance of the majority of the plasma HDL pool.

\section{Results}

Creation of liver-specific Abca1-knockout mice. Conditional targeting of the mouse $A b c a 1$ gene was achieved by flanking exons 45-46, which encode the second nucleotide-binding fold, with loxP sites, as depicted in Figure 1A (Floxed allele). Tissue-specific expression of Cre recombinase is predicted to eliminate exons 45-46 and result 


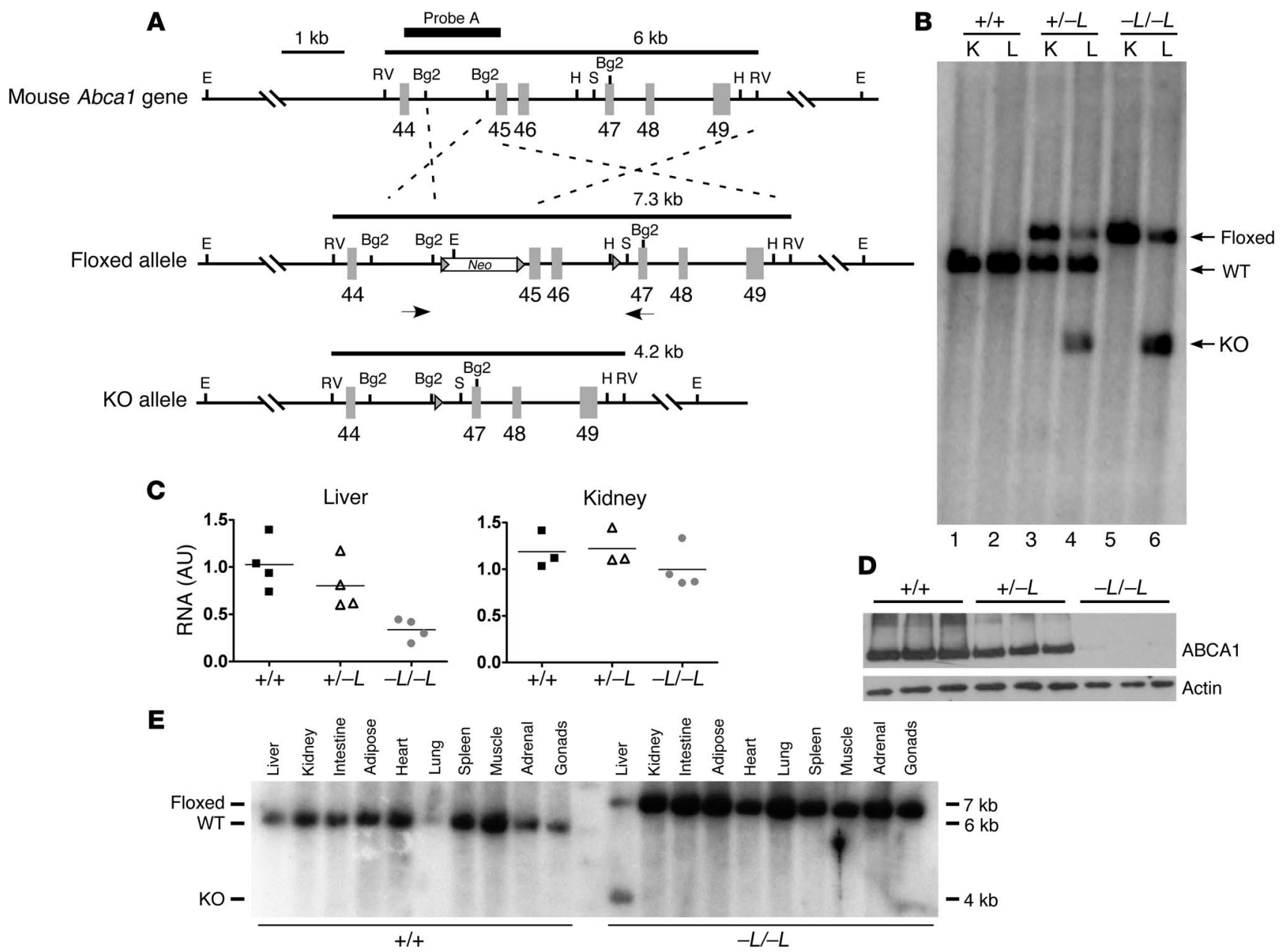

Figure 1

Targeting strategy and genotypic analysis of liver-specific Abca1-knockout mice. (A) Schematic of 3' region (exons 44-49) of Abca1 gene showing wild-type (top), floxed (middle), and knockout (bottom) Abca1 alleles. Three loxP sites, 2 flanking the neomycin (Neo) resistance gene and 1 in intron 46, are shown as arrowheads. Arrows below the floxed allele indicate relative position of primers used for PCR screen of alleles. The size of the EcoRV (RV) fragment is shown above each allele, and the relative location of the probe used for Southern blot analysis is shown above the wild-type allele (Probe A). Cre recombinase-mediated elimination of exons 45 and 46 will delete the second ATP-binding cassette, resulting in a knockout allele. Restriction sites: Bg2, Bgl II; E, EcoRI; H, HindIII; S, Sacl. (B) Southern blot analysis of liver (L) and kidney (K) genomic DNA from mice that inherited both the Cre and wild-type or floxed Abca1 alleles. DNA was digested with EcoRV and hybridized with probe A. $-L$ denotes a liver-specific knockout allele. (C) Quantitative real-time PCR analysis of RNA isolated from liver and kidney. Relative fold change compared with a wild-type $(+/+)$ liver sample was calculated using the $2^{-\Delta \Delta C T}$ method (42). (D) Western blot analysis of liver membranes isolated from 3 mice of the indicated Abca1 genotypes. (E) Multi-tissue Southern blot of genomic DNA from the indicated tissues from a wild-type and liver-specific knockout $(-L /-L)$ mouse.

in an inactive Abca1 protein. Eight of 267 embryonic stem cell clones surviving selection with G418 and ganciclovir were found to be correctly targeted by PCR and Southern blot analysis. However, only 2 of the correctly targeted clones were observed to have the loxP site in intron 46 after homologous recombination. This was determined by PCR amplification of a 500-bp fragment of genomic DNA including the HindIII site of intron 46, followed by DNA sequencing of the agarose gel-isolated PCR product. One of these clones was used to develop the mice described in this article.

The initial genotyping of mice was performed by PCR analysis of tail DNA, and presumptive genotypes were assigned to animals based on coinheritance of the Cre transgene, under control of the albumin promoter for liver-specific expression, and wild-type or floxed Abca1 alleles. To verify the initial genotypic assignment, we performed Southern blot analysis of genomic DNA from liver and kidney when animals were killed. Only the 6-kb wild-type allele was observed in DNA from liver and kidney in wild-type mice (Figure 1B, lanes 1 and 2). In heterozygous mice, both floxed and wild-type alleles were present in kidney DNA; however, liver DNA showed the presence of the predicted knockout allele $(4 \mathrm{~kb})$ and some residual floxed allele (7 kb), as well as the wild-type allele (6 kb) (lanes 3 and 4). In homozygous mice, only the floxed allele was observed in the kidney, but the liver contained predominantly the knockout allele (70\% based on PhosphorImager analysis; lane 6) and some residual floxed allele (30\%). We attribute the residual floxed allele to genomic DNA from nonhepatic cells (Kupffer, endothelial, white 
blood cells, etc.) in the liver sample, as described in other liver-specific knockout mice (16). Results from quantitative real-time PCR analysis of Abca1 mRNA demonstrated a gene dosage-dependent decrease in mRNA, to $30 \%$ of normal for $A b c a 1^{-L /-L}$ mice compared with wild-type littermates, in the liver but not in the kidney (Figure 1C). Western blot analysis of liver membranes also showed a gene dosage-dependent decrease in Abca1 protein to near undetectable levels in the homozygous knockout mice (Figure 1D). Multi-tissue Southern blot analysis demonstrated that only the liver DNA from $A b c a 1^{-L /-L}$ mice contained the knockout allele, whereas other tissues from this animal had only the floxed allele, and all tissues in the wild-type littermate control had only the wild-type allele (Figure 1E). These data show that Abca1 recombination and targeted deletion were specific for liver.

$P C$ and FC efflux from primary hepatocytes and elicited peritoneal macrophages. To ensure that the recombination of the floxed allele resulted in loss of Abca1 function, we isolated and cultured primary hepatocytes from $A b c a 1^{-L /-L}$ and $A b c a 1^{+/+}$mice and stimulated them with liver $X$ receptor/retinoid $X$ receptor (LXR/RXR) agonists prior to performing PC and FC efflux studies. FC (Figure $2 \mathrm{~A}$ ) and PL (Figure 2B) efflux from hepatocytes in the absence of lipid-free apoA-I was similar for both genotypes. However, in the presence of apoA-I, there was a significant $(P<0.01)$ stimulation of efflux for both lipids with hepatocytes derived from wild-type mice compared with those from $A b c a 1^{-L /-L}$ mice. In addition, no Abca1 protein was detected in hepatocytes from the knockout mice, whereas abundant protein was detected in wild-type controls (Figure 2D, top panel). These data confirm that our liver-specific knockout mice had no residual apoA-I-dependent Abca1 lipid efflux activity in hepatocytes. As a control, lipid efflux was measured in thioglycolate-elicited peritoneal macrophages from mice of the same genotype. Macrophages from wild-type and knockout mice showed the expected stimulation of cholesterol efflux in the presence of apoA-I and with additional treatment with the LXR agonist, T0901317 (Figure 2C). However, regardless of the experimental condition, efflux of cholesterol was similar for macrophages from wild-type and $A b c a 1^{-L /-L}$ mice. Abca 1 protein expression was also similar for cultured elicited macrophages from mice of both genotypes (Figure 2D, bottom).

Birth frequency of genotypes. Previous studies have documented that matings of homozygous $A b c a 1$-knockout ( $\mathrm{Abca1^{-- }}$ ) are nonproductive and lead to neonatal death as a result of placental malformation and fetal distress $(17,18)$. Consistent with these observations, we found the frequency of genotypes of our total Abca1-knockout ( $\left.A b c a 1^{-/}\right)$mice generated from intercross matings of $A b c a 1^{+/-E I I a-C r e ~ t r a n s g e n i c ~ m i c e ~ d i d ~ n o t ~ f o l l o w ~ M e n d e l i a n ~}$ inheritance $\left(\mathrm{Abca1}^{+/+}, 18 \% ; \mathrm{Abca1}^{+/-}, 69 \%\right.$; and $\left.\mathrm{Abca1}^{-/-}, 13 \% ; n=21\right)$. However, in the case of the liver-specific knockout, the frequency of genotypes derived from intercross matings of heterozygous liverspecific Abca1-knockout mice that inherited the Cre recombinase transgene (i.e., $A b c a^{+/-L(f l o x)} A l b-C r e T g$ ) was close to that expected for Mendelian inheritance $\left(A b c a 1^{+/+}, 22 \% ; A b c a 1^{+/-L}, 44 \%\right.$; and $A b c a 1^{-L /-L}$, $33 \% ; n=72$ ), which indicates that neither absence of hepatic Abca1 nor reduced HDL-C levels are responsible for the decreased fertility observed in $\mathrm{Abca1}^{-/-}$mice (19).

Plasma lipid and lipoprotein analysis. The plasma lipid and lipoprotein phenotype for chow-fed liver-specific $A b c a 1$ and $A b c a 1^{--}$mice after a 4-hour fast is shown in Table 1 . Total and HDL-C concentrations in plasma of $A b c a 1^{-L / L}$ mice were $80 \%$ lower than those of wild-type littermates $(P<0.001)$. Plasma FC, esterified cholesterol, and PL were all markedly lower in concentration (70-90\% reduction) in $A b c a 1^{-L /-L}$ mice compared with wild-type animals, and plasma triglyceride (TG) concentrations were significantly higher, which is consistent with the phenotype in Tangier disease patients (7). Plasma apoA-I, measured by ELISA, was also 90\% lower in $A b c a 1^{-L /-L}$ mice. Values for heterozygous mice were intermediate to those of wild-type and homozygous liver-specific knockout mice, which confirms a gene dosage effect of hepatic Abca1 expression on plasma lipid and HDL-C concentrations. Values for $A b c a 1^{-/-}$ mice, generated using EIIa-Cre transgenic mice, were slightly lower than those for $A b c a 1^{-L / L}$ mice. Lecithin cholesterol acyltransferase (LCAT) and hepatic lipase (HL) activities in plasma were 50\% lower in $A b c a 1^{-L /-L}$ compared with wild-type littermates (Table 1 ). However, PL transfer protein (PLTP) activity was reduced to background levels (i.e., equivalent to that in plasma of PLTP-knockout control mice; courtesy of Xian-Cheng Jiang, SUNY Downstate Medical Center, New York, New York, USA) in the $A b c a 1^{-L /-L}$ mice (Table 1).

Lipoprotein particle analysis. Given the striking decrease in plasma HDL-C levels of Abca1 $1^{-L / L}$ mice as determined by the hepa-

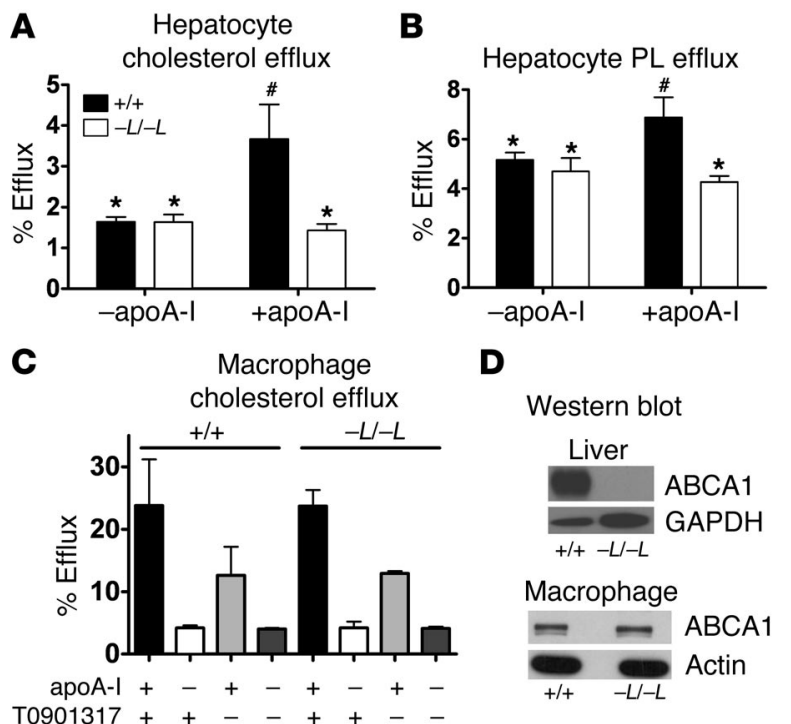

\section{Figure 2}

Lipid efflux from primary hepatocytes and peritoneal macrophages. Primary mouse hepatocytes were isolated from chow-fed $\mathrm{Abca1^{+/+ }}$ or Abca1-L/LL mice, stimulated with 9-cis-retanoic acid and 22-OH-cholesterol, and radiolabeled with either $\left[{ }^{3} \mathrm{H}\right]$ cholesterol or $\left[{ }^{14} \mathrm{C}\right]$ choline chloride for 24 hours. After an hour of equilibration, cells were incubated in the presence or absence of $10 \mu \mathrm{g}$ apoA-1/ml for 24 hours. (A) Hepatocyte cholesterol efflux in the presence or absence of apoA-I. (B) Hepatocyte choline PL efflux in the presence or absence of apoA-I. Data with unlike symbols are significantly different from one another $(P<0.05)$. (C) Thioglycolate-elicited peritoneal macrophages were isolated from $A b c a 1^{+/+}$or $A b c a 1^{-L / L}$ mice, radiolabeled with $\left[{ }^{3} \mathrm{H}\right]$ cholesterol for 24 hours, and then incubated with $10 \mu \mathrm{M}$ T0901317 or vehicle for an additional 24 hours. Cholesterol efflux was measured after 24-hour incubation of cells, which were stimulated with T0901317 or vehicle in the presence or absence of $20 \mu \mathrm{g}$ apoA-1/ml. Radiolabel in medium and the cellular isopropanol extract was quantified, and percentage efflux was calculated as the ratio of radioactivity in the medium divided by total radioactivity (cells + media) $\times 100 \%$. Data are mean \pm SD for 3 mice of the indicated genotypes, assayed in triplicate. (D) Western blot of Abca1 or load control protein (GAPDH or $\beta$-actin) in cultured hepatocytes (top) or cultured elicited macrophages (bottom). 


\section{Table 1}

Plasma measurements of liver-specific and Abca1-1- mice

\begin{tabular}{|c|c|c|c|c|c|c|c|c|c|c|}
\hline $\begin{array}{l}\text { Abca1 } \\
\text { genotype }\end{array}$ & $\begin{array}{c}\mathrm{TPC} \\
(\mathrm{mg} / \mathrm{dl})\end{array}$ & $\begin{array}{l}\text { HDL-C } \\
\text { (mg/dl) }\end{array}$ & $\begin{array}{c}\mathrm{FC} \\
(\mathrm{mg} / \mathrm{dl})\end{array}$ & $\begin{array}{c}E C \\
(\mathrm{mg} / \mathrm{dl})\end{array}$ & $\underset{(\mathrm{mg} / \mathrm{dl})}{\mathrm{PL}}$ & $\begin{array}{c}\mathrm{TG} \\
(\mathrm{mg} / \mathrm{dl})\end{array}$ & $\begin{array}{l}\text { apoA-I } \\
(\mathrm{mg} / \mathrm{dl})\end{array}$ & LCATA $^{\text {A }}$ & $\mathrm{HL}^{\mathrm{B}}$ & $\begin{array}{l}\text { PLTP } \\
\text { (AU) }\end{array}$ \\
\hline$t / t$ & $\begin{array}{c}109 \pm 17 \mathrm{c} \\
(27)\end{array}$ & $\begin{array}{c}88 \pm 16^{C} \\
(22)\end{array}$ & $\begin{array}{l}31 \pm 5^{c} \\
(6)\end{array}$ & $\begin{array}{c}73 \pm 21^{C} \\
(6)\end{array}$ & $\begin{array}{c}164 \pm 24 \mathrm{C} \\
(7)\end{array}$ & $\begin{array}{c}30 \pm 17^{c} \\
(7)\end{array}$ & $\begin{array}{c}186 \pm 67^{c} \\
(3)\end{array}$ & $\begin{array}{c}58 \pm 8^{c} \\
(3)\end{array}$ & $\begin{array}{c}11 \pm 2^{c} \\
(5)\end{array}$ & $\begin{array}{c}20,635 \pm 10,730^{\circ} \\
(5)\end{array}$ \\
\hline$+/-L$ & $\begin{array}{c}66 \pm 15^{D} \\
(18)\end{array}$ & $\begin{array}{c}59 \pm 110 \\
(9)\end{array}$ & $\begin{array}{c}19 \pm 2^{D} \\
(7)\end{array}$ & $\begin{array}{c}45 \pm 15^{D} \\
(7)\end{array}$ & $\begin{array}{c}125 \pm 26^{D} \\
(9)\end{array}$ & $\begin{array}{c}28 \pm 16 c \\
(7)\end{array}$ & $\begin{array}{c}162 \pm 42^{C} \\
\text { (3) }\end{array}$ & $\begin{array}{c}41 \pm 5^{C, D} \\
(3)\end{array}$ & $\begin{array}{c}9 \pm 1^{c} \\
(5)\end{array}$ & $\begin{array}{c}14,948 \pm 3,346 c \\
(5)\end{array}$ \\
\hline$-L /-L$ & $\begin{array}{c}19 \pm 7^{\mathrm{E}} \\
(17)\end{array}$ & $\begin{array}{c}12 \pm 6^{\mathrm{E}} \\
(17)\end{array}$ & $\begin{array}{c}5 \pm 2^{\mathrm{E}} \\
(7)\end{array}$ & $\begin{array}{c}12 \pm 4^{\mathrm{E}} \\
(7)\end{array}$ & $\begin{array}{c}56 \pm 14^{E} \\
(7)\end{array}$ & $\begin{array}{c}57 \pm 17^{D, E} \\
(7)\end{array}$ & $\begin{array}{c}14 \pm 4^{D} \\
(3)\end{array}$ & $\begin{array}{c}31 \pm 8^{D} \\
(3)\end{array}$ & $\begin{array}{c}5 \pm 1^{D} \\
(5)\end{array}$ & $\begin{array}{c}93 \pm 129 \mathrm{D} \\
(5)\end{array}$ \\
\hline$-1-$ & $\begin{array}{c}13 \pm 0.5^{E} \\
(3)\end{array}$ & $\begin{array}{c}8 \pm 1^{E} \\
(3)\end{array}$ & $\begin{array}{c}3 \pm 3^{E} \\
(3)\end{array}$ & $\begin{array}{c}10 \pm 3^{E} \\
(3)\end{array}$ & $\begin{array}{c}44 \pm 5^{E} \\
(3)\end{array}$ & $\begin{array}{c}36 \pm 6^{\mathrm{C}, \mathrm{E}} \\
(3)\end{array}$ & ND & ND & ND & ND \\
\hline
\end{tabular}

Values are mean \pm SD. Blood was obtained for analyses from chow-fed mice that were 9-12 weeks old (5-9 wks for Abca1-1- mice), after a 4-hour fast; the number of mice analyzed is given in parentheses. +/+, wild type; +/-L, heterozygous liver-specific knockout; -L/-L, homozygous liver-specific knockout; -/-, Abca1-/-; EC, esterified cholesterol; ND, not determined; TPC, total plasma cholesterol. ${ }^{\mathrm{A} L C A T}$, nmol cholesteryl ester formed/h/ml plasma; ${ }^{\mathrm{B} H L}$, $\mu \mathrm{mol}$ FA released/h/ml plasma. Values in the columns with superscripted letters $\mathrm{C}-\mathrm{E}$ are significantly different at $P<0.05$.

rin-manganese precipitation method, we investigated the size distribution and apolipoprotein content of the plasma lipoproteins. The distribution of cholesterol among lipoproteins after fractionation of plasma by fast performance lipid chromatography (FPLC) confirmed the profound reduction in HDL-C concentrations in $A b c a 1^{-L /-L}$ mice compared with wild-type controls (Figure $3 \mathrm{~A})$. The FPLC cholesterol elution profile also suggested a slight shift of the curve to the right in elution time of HDL particles for $A b c a 1^{+/-L}$ and $A b c a 1^{-L /-L}$ compared with wild-type mice, which suggests that the average size of HDL particles was smaller in these animals. However, nondenaturing gradient PAGE and apoA-I Western blot analysis revealed a similar size distribution for HDL particles in plasma of all 3 genotypes, which suggests that the decrease in plasma HDL concentration was due primarily to a decrease in the number of similar-sized particles (Figure $3 \mathrm{~B})$. There was also a decrease in cholesterol concentration in the LDL elution region of the FPLC column for heterozygous and homozygous mice, which is consistent with reported decreases in LDL concentration in patients with Tangier disease and in Abca1 $1^{-/-}$mice $(7,18,20)$.

To determine whether the apolipoprotein distribution of plasma lipoprotein particles was modified in $A b c a 1^{-L /-L}$ mice, we isolated by ultracentrifugation and analyzed them by SDS-PAGE (Figure $3 \mathrm{C}$ ). Overall, the apolipoprotein pattern among genotypes was similar except for an increase in the proportion of $\mathrm{apoB}_{48}$, albumin, and apoA-IV (by Western blot analysis; data not shown) and a relative decrease in apoA-I for $A b c a 1^{-L /-L}$ mice. These data, as well as the increase in plasma TG concentration (Table 1), suggest a modest accumulation of remnant lipoproteins of intestinal origin in the plasma of chow-fed liver-specific knockout mice.

Relationship of hepatic Abca1 expression and plasma HDL-C concentrations. To investigate the relationship between hepatic Abca1 protein expression and the steady-state concentration of plasma HDL among genotypes of liver-specific Abca1-knockout mice, we analyzed hepatic membrane Abca1 protein expression by Western blot analysis for a subset of mice and compared the results with the plasma concentration of HDL-C. There was a gene dosage effect on hepatic Abca1 protein expression (Figure 4A) that paralleled the decrease in plasma HDL-C concentration among liver-specific genotypes (Figure 4B), which suggests that the liver is the major source of plasma HDL particles in these chow-fed mice.
Plasma turnover and tissue uptake of wild-type HDL particles in liverspecific Abca1-knockout mice. Although ABCA1 is not thought to play a major role in the maturation and metabolism of mature plasma HDL particles (21), intravenously injected radiolabeled HDL from normal donors is rapidly cleared in patients with Tangier disease $(20,22)$, which suggests that ABCA1 may play a role in HDL catabolism. Similar observations have been made in studies on the Wisconsin hypoalpha mutant (WHAM) chicken, an animal model of Tangier disease in which the Abcal gene is functionally inactive $(23,24)$. We isolated HDL particles that were homogeneous in size from wild-type mice and radiolabeled them with $\left[{ }^{125} \mathrm{I}\right]$ tyramine cellobiose ([125I]TC), a residualizing reagent (25), to trace plasma decay and tissue uptake of HDL. The tracer HDL particles were $10.8 \mathrm{~nm}$ in diameter, and more than $80 \%$ of the radiolabeled protein migrated as apoA-I (Figure 5A). The radiolabeled HDL particles were injected into $A b c a 1^{+/+}, A b c a 1^{+/-L}$, and $A b c a 1^{-L /-L}$ recipient mice, and plasma decay of radiolabeled tracer was followed for 24 hours before the animals were sacrificed and tissues removed for quantification of tracer particle uptake. The plasma decay of radiolabeled tracer was more rapid with progressive inactivation of liver $A b c a 1$ alleles (Figure 5B). $A b c a 1^{-L /-L}$ mice had a 2 -fold greater tracer fractional catabolic rate (FCR) compared with wild-type littermate recipient mice $(2.88 \pm 0.14$ vs. $1.68 \pm 0.61$ pools/day; $P<0.02)$, whereas heterozygous recipient mice had an intermediate FCR ( $2.00 \pm 0.12$ pools/day) (Figure 5C). Production rate, calculated as the product of plasma apoA-I pool size and plasma FCR, was 10-fold higher in wild-type compared with $A b c a 1^{-L /-L}$ mice $(3.1 \pm 1.7$ vs. $0.33 \pm 0.09 \mathrm{mg}$ apoA-I/d; $P<0.03)$. We interpret this as the production rate of HDL particles, since apoA-I synthesis and secretion are normal in Tangier patients, $A b c a 1^{-/-}$mice, and the WHAM chicken $(7,24,26)$. Monitoring of HDL tracer size in plasma during the 24-hour turnover by nondenaturing gradient PAGE and PhosphorImager analysis showed no discernible shift in HDL particle size (Figure 5D), which suggests that HDL particles were catabolized from plasma without major remodeling. Previous studies have shown that the major sites for HDL apoA-I uptake are the liver and kidney (27-29). Uptake of tracer HDL by the liver, which included tracer that was recovered in the intestine and intestinal contents (30), was not different among genotypes and was nearly 3 -fold greater than that observed for kidney uptake in wild-type mice (19.3\% vs. $7.3 \%$; Figure 5E). However, there was a 

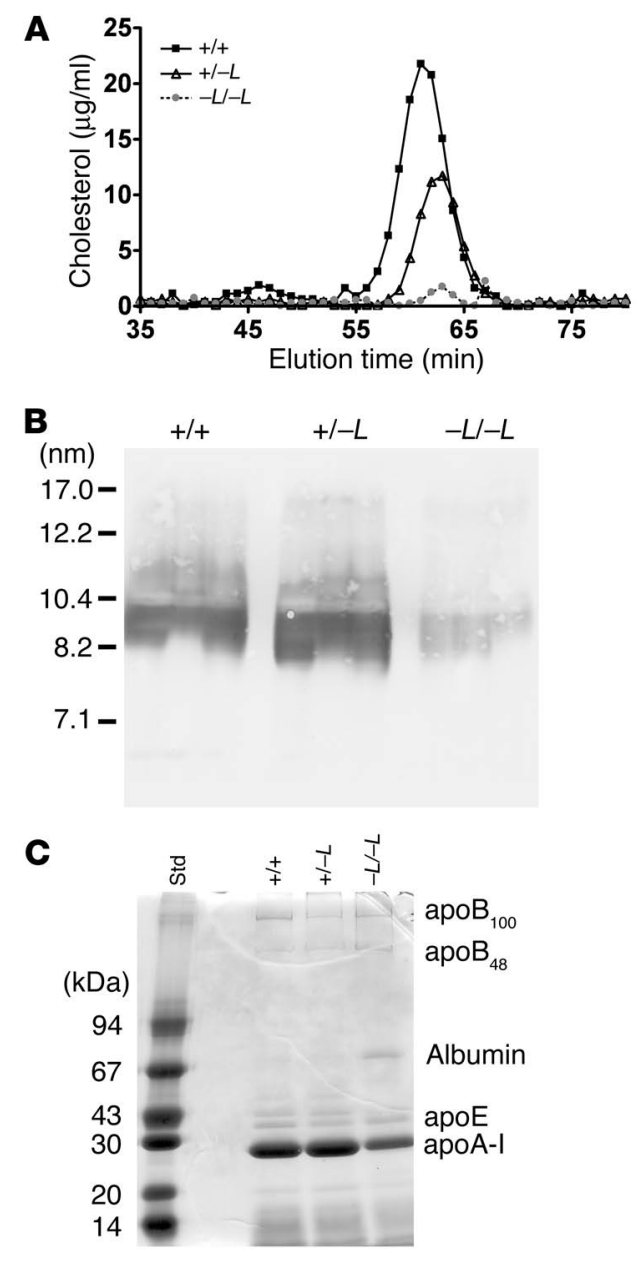

significant increase in tracer HDL uptake by the kidney with progressive inactivation of hepatic $A b c a 1$ alleles, which resulted in a 2 -fold increase in tracer HDL uptake in $A b c a 1^{-L / L}$ compared with wild-type mice (12.4\% vs. $7.3 \%$ of injected dose, respectively).

Plasma turnover and tissue uptake of lipid-free apoA-I in liver-specific Abca1-knockout mice. To determine the role of hepatic Abca1 on apoA-I catabolism, we performed turnover studies in Abca1-knockout mice using purified human lipid-free $\left[{ }^{125} \mathrm{I}\right] \mathrm{TC}$ apoA-I tracer. The tracer migrated as authentic apoA-I on a SDS-PAGE gel, with a size range of less than $7.1 \mathrm{~nm}$ on nondenaturing gradient gels, and contained less than 1 molecule of PL per molecule apoA-I (Figure 6A) (28). Plasma turnover of apoA-I (Figure 6B) was more rapid for $A b c a 1^{-L / L}$ recipients compared with wild-type mice, with a 2 -fold greater tracer FCR (3.98 \pm 0.34 vs. $1.95 \pm 0.04$ pools/day, respectively; $P<0.001$; Figure 6C). Lipid-free apoA-I tracer FCR was significantly higher than that of HDL tracer in $A b c a 1^{-L /-L}$ mice (3.98 vs. 2.88 pools/day; $P<0.003$ ), whereas there was no difference in plasma FCR for these tracers in wild-type mice ( 1.95 vs. 1.68 pools/ day, respectively). apoA-I tracer was found to be bound to mouse HDL particles in plasma throughout the 24-hour turnover study (Figure 6D), with no tracer observed in the migration position of lipid-free apoA-I (<7.1 nm; Figure 6A). As observed for the HDL turnover study, while there was no difference in liver uptake of the apoA-I tracer, there was a 2.3-fold increase in kidney uptake in $A b c a 1^{-L /-L}$ compared with wild-type recipients (Figure 6E). Radio-

\section{Figure 3}

Plasma lipoprotein and apolipoprotein characterization of liver-specific Abca1-knockout mice. Plasma was obtained from chow-fed Abca1+/+, $A b c a 1^{+/ L}$, and $A b c a 1^{-L / L}$ mice fasted for 4 hours. Equal-volume pools of plasma were made using 5 mice of each genotype for FPLC $(\mathbf{A})$ and apolipoprotein analysis (C). (A) One hundred microliters whole plasma from each pool was fractionated on Superose 6 FPLC columns. Fractions were collected at 1-minute intervals, and total cholesterol was measured using an enzymatic assay. (B) One microliter of whole plasma from 3 individual mice of each genotype was fractionated on a $4-30 \%$ nondenaturing gradient gel for $1,400 \mathrm{~V} / \mathrm{h}$. The proteins were transferred to nitrocellulose, and the blot was developed with antimouse apoA-I antiserum. (C) Pooled plasma from each genotype was subjected to ultracentrifugation at a density of $1.25 \mathrm{~g} / \mathrm{ml}$ to float plasma lipoproteins. Fifteen micrograms of lipoprotein protein was added to each lane of the gel, and apolipoproteins were separated by $4-16 \%$ SDS-PAGE. Gels were stained with Coomassie blue and destained to visualize the apolipoproteins. Standard low-molecular-weight markers $(\mathrm{Std})$ are indicated on the left. Estimated migration position of $\mathrm{apoB}_{100}$, $\mathrm{apoB}_{48}$, albumin, apoE, and apoA-I are indicated on the right.

label recovery in the liver and intestine was lower in the apoA-I tracer turnover study compared with that in the HDL study for 2 reasons. First, the more rapid removal of $\left[{ }^{125} \mathrm{I}\right] \mathrm{TC}$ apoA-I from the plasma compartment compared with [ $\left.{ }^{125} \mathrm{I}\right] \mathrm{TC}$ HDL likely resulted in a greater loss of radiolabel from the liver and kidney into the feces and urine during the time course of the turnover $(27,30)$. Second, the liver uptake data in the HDL turnover study included radiolabel that had leaked into the intestine $(27,30)$, whereas the apoA-I turnover study did not.

\section{Discussion}

Studies in patients with Tangier disease and Abca1-knockout mice have shown that efflux of lipid by ABCA1 is the rate-limiting step in HDL particle formation and is absolutely required for the maintenance of plasma HDL-C concentrations $(18,20,31)$. ABCA1 is variably expressed in nearly all tissues of the body, and its major function is to assemble FC and PL with lipid-free apoA-I to form nascent HDL particles (32). However, only 2 tissues, the liver and intestine, synthesize and secrete apoA-I (15). In addition, adenoviral and transgenic overexpression of hepatic ABCA1 increases plasma HDL-C concentrations (11-13), which suggests that the liver may contribute to the plasma HDL pool. Using a liver-specific Abca1-knockout mouse model, we provide what we believe to be the first definitive proof that hepatic Abca1 is essential for approximately $80 \%$ of the steady-state pool of plasma HDL in chow-fed mice and that the gene dosage-dependent decrease in plasma HDL-C is matched by a similar decrease in hepatic Abca1 protein expression. These results support an unequivocal and essential role for hepatic Abca1 in HDL production in an experimental setting in which mice were fed a chow diet and Abca1 was not upregulated by cholesterol feeding or LXR activation. The finding that plasma HDL-C and apoA-I levels were reduced by $80 \%$ and $90 \%$, respectively, in the absence of hepatic Abca1 but in the presence of functional Abca 1 in extrahepatic tissues, also suggests that lipidation of the nascent apoA-I molecule occurs during or soon after secretion by hepatocytes, prior to entry of the particle into the circulation. This finding is in agreement with studies in cell culture models, which indicate that hepatocyte lipidation of apoA-I occurs in an intra- or pericellular fashion $(33,34)$. Our data also suggest that lipidation by hepatocytes is necessary for main- 

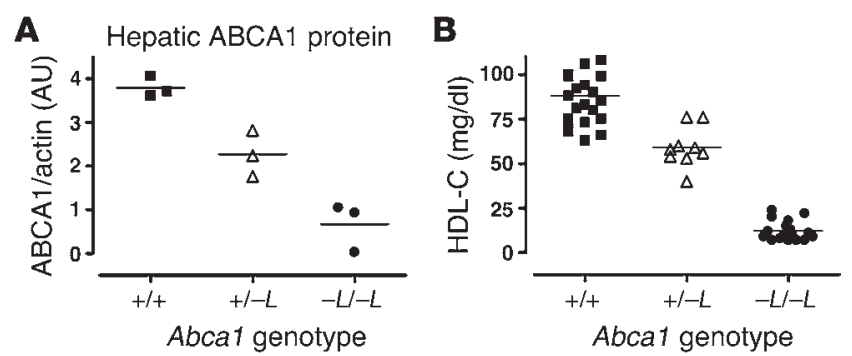

Figure 4

Hepatic Abca1 protein expression and plasma HDL cholesterol concentrations in liver-specific Abca1-knockout mice. Liver membranes were isolated from a subset of mice of the indicated genotypes that were allowed to consume chow. Membranes were fractionated by SDSPAGE, after which proteins were transferred to nitrocellulose membranes and probed with primary antibody to Abca1 or $\beta$-actin. Blots were developed using a ${ }^{125}$ I-radiolabeled secondary antibody, and Phosphorlmager analysis was then used to quantify the signal intensity ratio of Abca1 to $\beta$-actin (A). HDL cholesterol concentrations in plasma were measured by enzymatic assay after precipitation of apoB lipoproteins with heparin and $\mathrm{MnCl}_{2}$ (B). Points represent data from individual mice, and the horizontal lines denote the mean for each genotype.

taining plasma HDL concentrations by prolonging the circulation time of HDL apoA-I in vivo.

HDL particle assembly in vivo is complex and poorly understood. The demonstration that fibroblasts from patients with Tangier disease are unable to mediate the efflux of FC and PL to lipid-free apoAI, and the discovery that mutations in $A B C A 1$ cause Tangier disease, established $\mathrm{ABCA} 1$ as the key molecule regulating the formation of nascent HDL. The identification of the sites of in vivo HDL biogenesis is fundamental to our understanding of RCT. This pathway, as originally envisioned by Glomset (2), involves the release of cellular cholesterol from extrahepatic tissues. Assembly of lipid-free apoA-I with PL and FC in peripheral tissues would provide a source of nascent HDL particles, which, upon maturation to spherical HDL in plasma by LCAT and PLTP, would direct the flux of cholesterol to the liver upon subsequent HDL particle catabolism by this organ. However, studies using Abca1-knockout bone marrow transplanted into wild-type mice do not support a major role for macrophage $\mathrm{ABCA} 1$ in the maintenance of plasma HDL concentrations (14). Results from our study, involving selective deletion of hepatic $A b c a 1$, demonstrate that the liver is the major source of plasma HDL and hepatic Abca1 maintains the pool of plasma HDL by lipidating newly secreted apoA-I to produce nascent HDL particles that undergo maturation in plasma. These results therefore profoundly alter our concept of in vivo HDL particle assembly by establishing the liver as the single most important source of nascent HDL in chow-fed mice.

Since efflux of FC from cells in culture to plasma HDL particles by non-ABCA 1 pathways is quantitatively greater than that observed for lipid-free apoA-I by ABCA1 pathways, the main role of liver ABCA1 may be to provide plasma HDL particles to participate in RCT by pathways other than ABCA1, such as those mediated by scavenger receptor class B, type I (SR-BI) and ABCG1 $(35,36)$. Efflux of FC from lipid-loaded macrophages by ABCA1 is an important antiatherogenic pathway of the RCT pathway, since transplantation of $\mathrm{Abca1}^{-/-}$macrophages into atherosclerosis-susceptible mice results in increased atherosclerosis; however, this RCT pathway is not quantitatively important in maintaining plasma HDL levels $(14,37,38)$. The relative importance of RCT via macrophage $A B C A 1$ versus non-ABCA1 HDL efflux pathways with regard to atherosclerosis development is unknown and will require further investigation.

Normal HDL particles are hypercatabolized in patients with Tangier disease and the WHAM chicken (20,22, 24). Hypercatabolism of plasma HDL tracer has been shown to occur even after normalization of HDL-C levels in patients with Tangier disease $(22,39)$. We observed an increased turnover of wild-type plasma HDL apoA-I in mice with progressive inactivation of hepatic $A b c a 1$ alleles (Figure 5, B and C). However, increased catabolism of the tracer was only observed in the kidney, even though the liver was responsible for approximately 3 -fold more HDL apoA-I catabolism than the kidney in wild-type mice (Figure 5E). These data argue against a nonspecific hypercatabolism of the HDL apoA-I tracer due to a lower HDL pool size in the $A b c a 1^{-L / L}$ mice and are compatible with the observation that repletion of the plasma HDL pool in Tangier patients does not correct the hypercatabolism of HDL. Since HDL particles do not bind to ABCA1 with high affinity and are not efficient acceptors of ABCA1-mediated lipid efflux compared to lipid-free apoA-I $(21,40)$, why should hypercatabolism of normal HDL apoA-I occur in the absence of Abca1? We suggest that following selective uptake of HDL cholesteryl ester by SR-BI in the liver, lipid-free or lipid-poor apoA-I is released from the remodeled HDL particle and immediately relipidated by Abca1 at the hepatocyte surface before reentry into plasma, which results in a renewable source of nascent HDL particles that can enter the plasma HDL pool after being processed to mature particles. Our data also suggest that functional Abca1 in extrahepatic tissues is not sufficient to relipidate and recycle the apoA-I that is released at the hepatocyte surface during HDL catabolism, because in the absence of hepatic Abca1, lipid-free or lipid-poor apoA-I is not relipidated, enters the circulation, and is rapidly cleared by the kidney. This argument is also supported by the significantly more rapid turnover of lipid-free apoA-I tracer (Figure 6) compared with that of HDL tracer (Figure 5) in $A b c a 1^{-L / L}$ mice, which suggests that extrahepatic Abca1 expression in chow-fed mice is not sufficient to rescue the hypercatabolism of lipid-free apoA-I from plasma. Thus, we believe that the maintenance of plasma HDL concentrations by hepatic Abca 1 is achieved by 2 mechanisms, the lipidation of newly secreted hepatic apoA-I and the recycling of some proportion of apoA-I after catabolism of HDL particles at the hepatocyte surface.

\section{Methods}

Generation ofliver-specific Abca1-knockout mice. A duplication/deletion targeting vector (Osdupdel; courtesy of Oliver Smithies, University of North Carolina, Chapel Hill, North Carolina, USA) was used to generate the targeting construct. Briefly, the short and long arms of the targeting construct were derived from a 6.4-kb BamHI fragment that was detected by screening a $129 /$ SvEv genomic DNA $\lambda$ phage library (provided by Hyung-Suk Kim, University of North Carolina, Chapel Hill, North Carolina, USA) with a PCR-generated probe spanning intron 44 (probe A; Figure 1A). The short arm consisted of a 1.2-kb BglII fragment from intron 44, and the long arm consisted of a 4.3-kb region from the downstream BglII site of intron 44 to the EcoRV site in intron 49. A loxP site, in addition to the 2 flanking the neomycin resistance gene, was introduced into the targeting vector at the HindIII site in intron 46, such that exons 45-46, which encode the second nucleotide-binding fold, were flanked by loxP sites (Figure 1A). The targeting construct was electroporated into 129/SvEv Tac embryonic 
A Nondenaturing

gradient gel

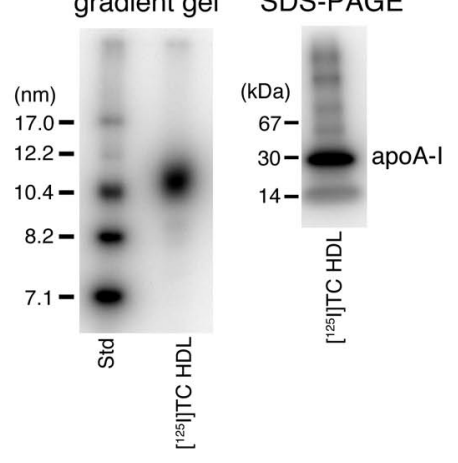

D

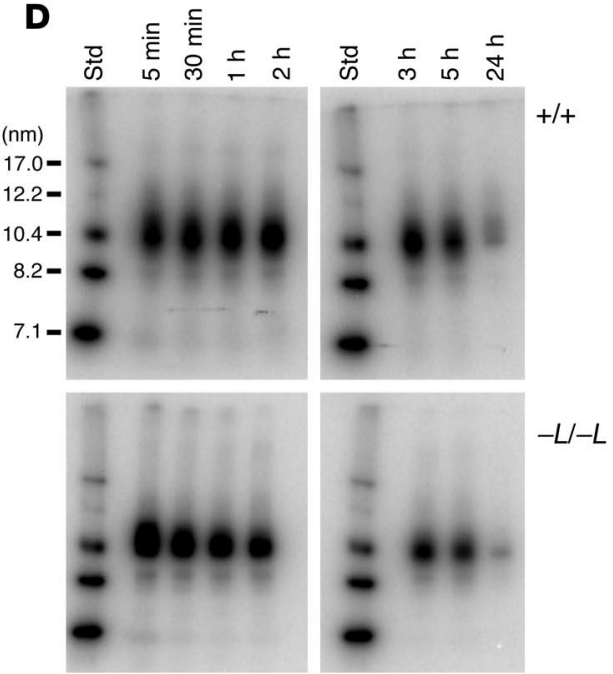

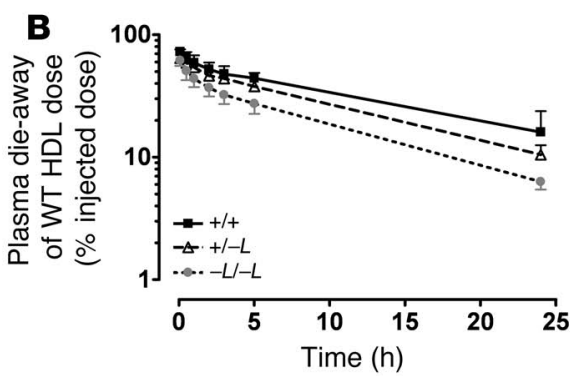

C

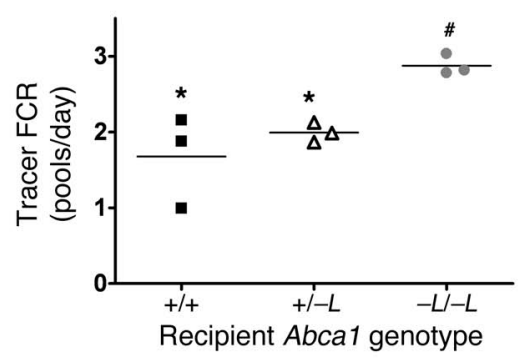

$\mathbf{E}$

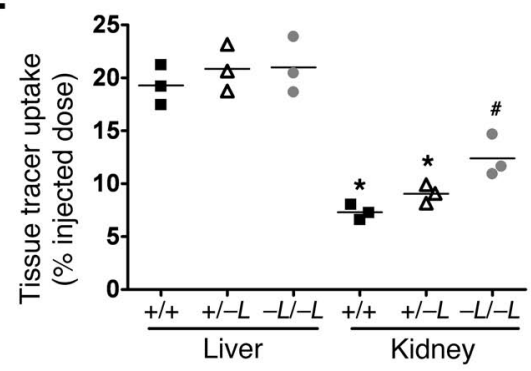

Figure 5

In vivo catabolism of wild-type HDL tracer in $A b c a 1^{+/+}, A b c a 1^{+/ L}$, and $A b c a 1^{-L /-L}$ recipient mice. HDL particles were isolated from the plasma of chow-fed wild-type mice, radiolabeled with [125I]TC, a residualizing reagent, and injected into chow-fed mice of the indicated genotype. Plasma samples were taken over 24 hours, after which animals were sacrificed, and tissues were harvested for quantification of radiolabel uptake. In $\mathbf{C}$ and $\mathbf{E}$, genotypes with unlike symbols are significantly different from one another $(P<0.05)$. (A) Characterization of $\left[{ }^{125} \mid\right] T C$ HDL tracer by $4-30 \%$ nondenaturing gradient gel electrophoresis and $4-16 \%$ SDS-PAGE. Both gels were visualized by Phosphorlmager analysis. Standard proteins are shown for reference. (B) Whole plasma die-away of wild-type $\mathrm{HDL}$ tracer in $A b c a 1^{+/+}, A b c a 1^{+/ L}$, and $A b c a 1^{-L /-L}$ mice. Individual data points are mean \pm SD $(n=3)$. (C) Tracer FCR calculated from the plasma die-away curves in $\mathbf{B}$. The horizontal lines denote the mean for each genotype. (D) Size analysis of [125I]TC HDL tracer in plasma after injection into $A b c a 1^{+/+}$and $A b c a 1^{-L / L}$ recipient mice. Plasma samples were collected at the indicated times from recipient mice injected with [125]]TC HDL and separated on 4-30\% nondenaturing gradient PAGE. [125]]TC HDL migration was visualized by Phosphorlmager analysis. (E) Liver and kidney uptake of [125I]TC HDL tracer 24 hours after injection into Abca1 $1^{+/+}, A b c a 1^{+/ L L}, A b c a 1^{-L /-L}$ mice. Liver (including intestine and contents; ref. 30) and kidney tissue was digested overnight in $1 \mathrm{~N} \mathrm{NaOH}$ at $60^{\circ} \mathrm{C}$, and ${ }^{125}$ r radioactivity in the digest was quantified using a $\gamma$-ray counter.

stem cells, which were then subjected to positive and negative selection for homologous recombination with G418 and ganciclovir, respectively. Surviving embryonic stem cells were screened by PCR and Southern blot analysis (see below), and correctly targeted cells were expanded and injected into C57BL/6 (B6) mouse blastocysts and implanted into pseudopregnant B6 female mice. We bred agouti male mice to B6 female mice to test for germline transmission of the conditionally targeted allele (i.e., floxed

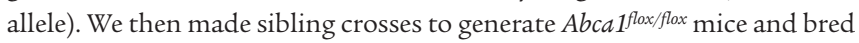
these mice with $\mathrm{B} 6$ mice expressing the Cre transgene under control of the albumin promoter (C57BL/6-Tg(Alb-Cre) $21 \mathrm{Mgn} / \mathrm{J}$; The Jackson Labora- tory) to generate heterozygous liver-specific Abca1-knockout mice $\left(A b c a 1^{+/-L}\right)$; or with B6 mice expressing the Cre transgene under the control of the EIIa promoter (B6.FVB-Tg(EIIaCre) C57379 Lmgd/J; The Jackson Laboratory) to generate heterozygous $A b c a 1$-knockout mice $\left(A b c a 1^{+/-}\right)$. Intercrosses of the latter mice (Abca1 ${ }^{+/-L} \mathrm{Alb}$-Cre or Abca1 $\left.1^{+/-E I I a-C r e}\right)$ were made to generate the mice used for this study. All animal procedures were approved by the Wake Forest University School of Medicine Animal Care and Use committee.

PCR, Southern blot, and real-time PCR analysis of liver-specific Abca1-knockout mice. We performed initial genotyping of offspring by PCR using genomic DNA isolated from tail biopsies (41). The following primers were used to determine the inheritance of the Cre transgene and $\mathrm{Abca} 1$ alleles $(+/+,+$ /flox, flox/flox): Cre 4 forward GGACATGTCAGGGATCGCCAGGCG and Cre 5 reverse GCATAACCAGTGAAACAGCATTGCTG; Abca1 wild-type allele Abc5' GTCCAAGTTCACTACCTGGA and Abc5 reverse GCAGACTGCCACTTATTCCTC; $A b c a 1$ floxed allele Abc 5' and Neo reverse TATGGCGCGCCATCGATCTCGA. Presumptive genotypes were assigned based on the PCR results, and when animals were sacrificed, verification of the genotype was determined using Southern blot analysis of genomic DNA isolated from liver and other tissues. Southern blot analysis was carried out after an EcoRV (Promega) digestion of genomic DNA isolated from indicated tissues, following a proteinase K digestion. Digested DNA was fractionated on a $0.8 \%$ agarose gel and transferred to a Nytran SuperCharge Nylon Transfer Membrane (Schleicher \& Schuell BioScience). Southern blots were hybridized with a probe spanning intron 44 (Figure 1A), yielding 6-kb, 7-kb, and 4-kb fragments for wild-type, floxed, and knockout alleles, respectively. RNA was isolated using TRIzol reagent according to the manufacturer's instructions (Invitrogen Corp.). RNA was diluted to a $1 \mu \mathrm{g} / \mu \mathrm{l}$ stock and then reverse transcribed to generate CDNA that was the template for real-time PCR using SYBR Green PCR Master Mix (Applied Biosystems) in an ABI Prism 7700 Sequence Detection System (Applied Biosystems). Primers for real-time PCR for Abca1 were: forward (mAbcA1 198), CGTTTCCGGGAAGTGTCCTA and reverse (mAbcA1 276), GCTAGAGATGACAAGGAGGATGGA. Reverse transcription was carried out using the Omniscript RT Kit (QIAGEN) with incubation conditions of $37^{\circ} \mathrm{C}$ for 60 minutes, followed by denaturation at $95^{\circ} \mathrm{C}$ for 5 minutes. Data were analyzed using the $2^{-\Delta \Delta C T}$ method (42).

Plasma analyses. We conducted phenotypic measurements using $A b c a 1^{+/+}$, $A b c a 1^{+/-L}, A b c a 1^{-L /-L}$, and $A b c a 1^{-/-} F_{2}$ generation littermates fed a chow diet (Prolab RMH 3000 rodent diet; LabDiet). Plasma was isolated from blood collected through the tail vein after a 4-hour fast. Plasma lipid concentra- 


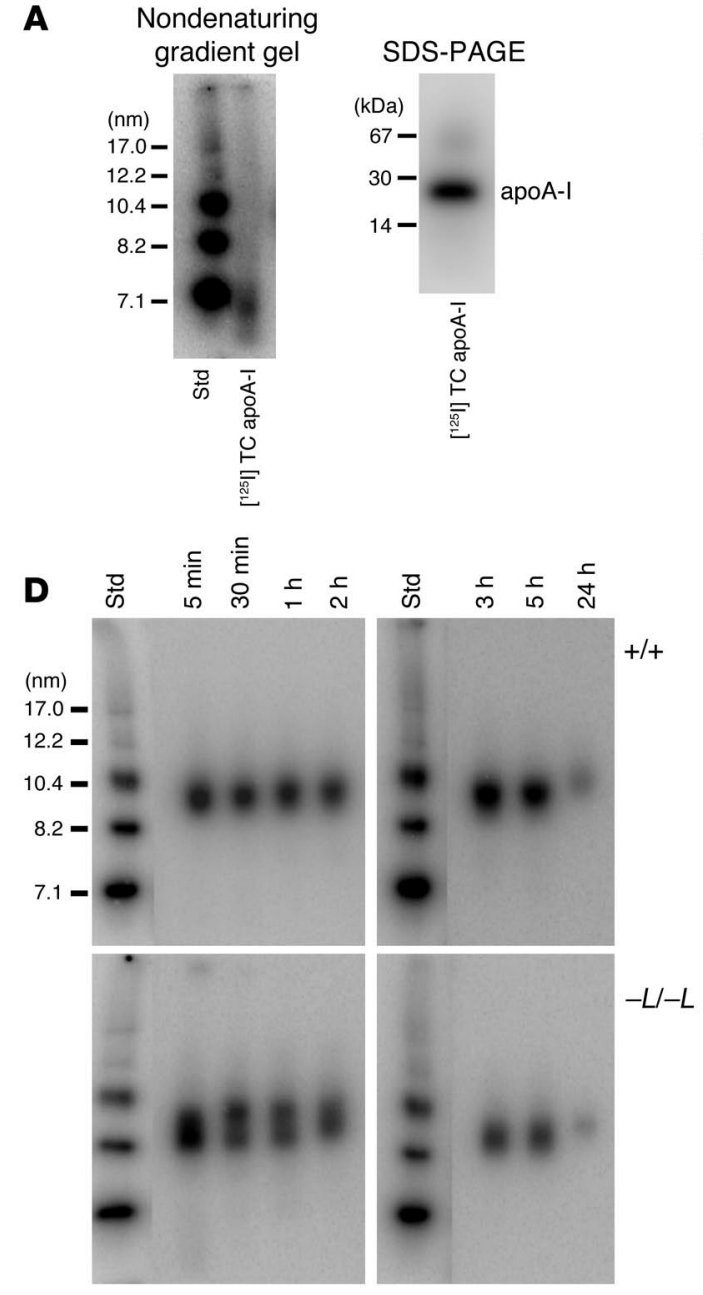

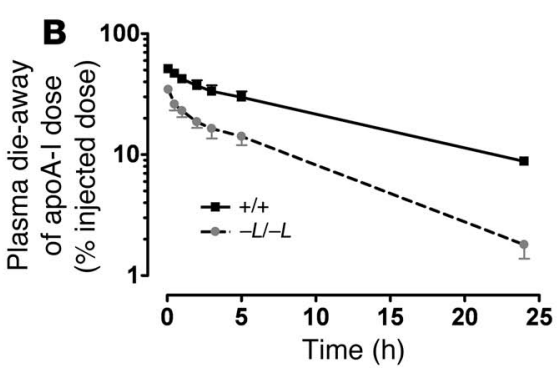

C

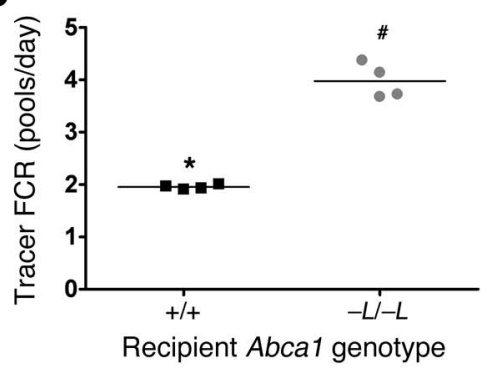

$\mathbf{E}$

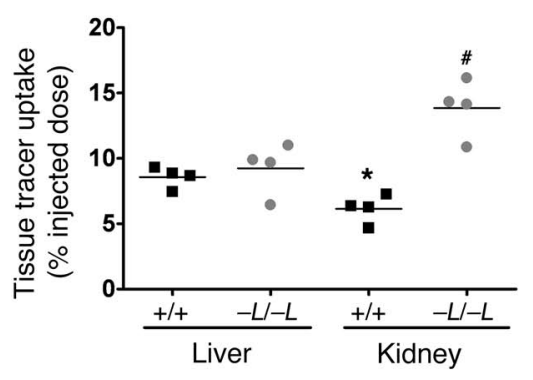

Figure 6

In vivo catabolism of human lipidfree apoA-I tracer in $A b c a 1^{+/+}$and Abca $1^{-L / L}$ recipient mice. apoA-I was isolated from human plasma, radiolabeled with [125I]TC, and injected into chow-fed mice of the indicated genotype. Details are presented in the Figure 5 legend. (A) Phosphorlmager analysis of [125I]TC apoA-I tracer after separation by $4-30 \%$ nondenaturing gradient gel electrophoresis and 4-16\% SDS-PAGE. (B) Whole plasma die-away of lipid-free apoA-I tracer in $\mathrm{Abca}^{+/+}$and $A b c a 1^{-L /-L}$ mice. Individual data points are mean $\pm \mathrm{SD}$ $(n=4)$. (C) Tracer FCR calculated from the plasma die-away curves in $\mathbf{B}$. The horizontal lines denote the mean for each genotype. (D) Size analysis of [125I]TC apoA-I tracer in plasma after injection into $A b c a 1^{+/+}$and $A b c a 1^{-L / L}$ recipient mice. (E) Liver and kidney uptake of [125I]TC apoA-I tracer 24 hours after injection into Abca1+/+ and $A b c a 1^{-L / L}$ mice. Liver and kidney tissue was digested overnight in $1 \mathrm{~N}$ $\mathrm{NaOH}$ at $60^{\circ} \mathrm{C}$, and ${ }^{125} \mathrm{I}$ radioactivity in the digest was quantified using a $\gamma$-ray counter. Genotypes with unlike symbols are significantly different from one another $(P<0.001)$. tions were determined by enzymatic assay (43). To measure plasma HDL-C concentration, one-tenth volume of $4 \%$ heparin in $2 \mathrm{M} \mathrm{MnCl}_{2}$ was added to plasma to precipitate apoB lipoproteins, the plasma was incubated on ice for 30 minutes, and the supernatant was isolated after a 1,500-g centrifugation for 30 minutes. Supernatants were assayed for total cholesterol as described previously (43).

apoA-I levels were measured by a sandwich ELISA similar to that reported previously (44). Briefly, immunoaffinity-purified anti-mouse apoA-I antibody (BIODESIGN International) was used for capture and detection, after an aliquot was derivatized with HRP. The assay was log-linear from 0.5 to $250 \mathrm{ng}$ apoA-I/well, and purified mouse apoA-I (BIODESIGN International) was used as standard. Plasma was diluted $2 \times 10^{4}$ - to $8 \times 10^{4}$-fold for $A b c a 1^{1++}$ and $A b c a 1^{+/-L}$ mice and $0.25 \times 10^{4}$ - to $1 \times 10^{4}$-fold for $A b c a 1^{-L /-L}$ mice before assay.

LCAT activity in plasma was measured using a recombinant HDL substrate containing 1-palmitoyl-2-oleoyl-sn-glycero-3-phosphocholine, cholesterol, and apoA-I as described previously (45). PLTP activity was measured with a commercially available fluorescent assay kit (Cardiovascular Target) following the manufacturer's instructions. HL activity was measured in plasma using a radiolabeled triolein-Triton X-100 mixed micellar substrate as described previously (46).

Lipoprotein particle characterization. The distribution of plasma lipoproteins was determined after fractionation of whole plasma by FPLC using two Superose $6(1 \times 30 \mathrm{~cm})$ columns (Amersham Biosciences) in series, followed by total cholesterol enzymatic assay of each fraction. To determine the size distribution of HDL particles, we applied 1-3 $\mu$ l of whole plasma to a $4-30 \%$ nondenaturing gradient gel for electrophoretic separation and Western blot analysis as described previously (43). To qualitatively assess the apolipoprotein composition of the plasma lipoproteins, we subjected $200 \mu \mathrm{l}$ of pooled plasma from each genotype to ultracentrifugation at a density of $1.25 \mathrm{~g} / \mathrm{ml}$ and separated $15 \mu \mathrm{g}$ of lipoprotein protein by $4-16 \%$ SDS PAGE as described previously (47). Gels were stained with Coomassie blue and destained with acetic acid/methanol to visualize protein bands.

Hepatocyte and macrophage isolation and efflux. Primary hepatocytes were isolated from wild-type and $A b c a 1^{-L /-L}$ mice as previously described (48). Briefly, following a liver perfusion with a $0.01 \%$ collagenase solution through the portal vein, hepatocytes were plated at a $75 \%$ confluency in DMEM (Invitrogen Corp.) supplemented with 10\% FBS (Invitrogen Corp.), $20 \mathrm{mU} / \mathrm{ml}$ insulin (Novo Nordisk Pharmaceuticals), $1 \mathrm{mM}$ sodium pyruvate (Invitrogen Corp.), and $25 \mathrm{nM}$ dexamethasone (SigmaAldrich). The following day, Abca1 expression was stimulated by the addition of $20 \mathrm{mM}$ 9-cis-retanoic acid (Sigma-Aldrich) and $8 \mu \mathrm{g} / \mathrm{ml}$ 22-R-hydroxycholesterol (Steraloids Inc.), and cells were radiolabeled with $2 \mu \mathrm{Ci} / \mathrm{ml}\left[{ }^{3} \mathrm{H}\right]$ cholesterol or $10 \mu \mathrm{Ci} / \mathrm{ml}\left[{ }^{3} \mathrm{H}\right]$ choline chloride (PerkinElmer). Efflux was performed as previously described (49, 50). Differences among samples were compared with a 1-way ANOVA test and Newman-Keuls post-hoc test. Abca1 expression was determined in hepatocyte lysates by SDS-PAGE using an anti-Abca1 monoclonal antibody and antiGAPDH as loading control, as previously described (32). 
Macrophages were obtained from the peritoneal cavity of wild-type and $A b c a 1^{-L / L}$ mice 4 days after intraperitoneal injection of $1 \mathrm{ml}$ of $10 \%$ thioglycolate. The cells obtained were washed with Media A (MEM + $10 \mathrm{mM}$ HEPES; Cellgro [Mediatech Inc.]), spun at $100 \mathrm{~g}$ for 20 minutes, and plated in 12-well plates at a density of $6 \times 10^{5}$ cells/well in MEM supplemented with $10 \% \mathrm{FBS}, 100 \mathrm{U} / \mathrm{ml}$ penicillin, $100 \mu \mathrm{g} / \mathrm{ml}$ streptomycin, $1 \%$ MEM vitamin solution $100 \times$ (Mediatech Inc.), and $2 \mathrm{mM}$ L-glutamine. Cells were washed 2 hours later and incubated for 2 days. On the third day, cells were radiolabeled with $2 \mu \mathrm{Ci} / \mathrm{ml}\left[{ }^{3} \mathrm{H}\right]$ cholesterol for 24 hours, washed, and incubated with the LXR agonist, $10 \mu \mathrm{M}$ T0901317 (TO-901317; SigmaAldrich), or vehicle (DMSO) for 24 hours. Cells were incubated with $10 \mu \mathrm{M}$ T0901317 or vehicle for an additional 24 hours in the presence or absence of lipid-free apoA-I $(20 \mu \mathrm{g} / \mathrm{ml})$, isolated, and characterized as previously described (28). After 24-hour incubation, medium was removed, spun at $12,500 \mathrm{~g}$ for 30 minutes, and assayed for radioactivity. Cells were washed with ice-cold PBS, lipids were extracted with isopropanol for 24 hours, and the isopropanol extract was assayed for radioactivity.

Abca1 protein expression in macrophages was determined by Western blot analysis of total cell protein after lysis of cells in buffer containing $150 \mathrm{mM} \mathrm{NaCl}, 25 \mathrm{mM}$ Tris-HCl, and $1 \%$ Triton X-100. Fifty micrograms of total cell protein was incubated at $37^{\circ} \mathrm{C}$ for 30 minutes and subjected to 4-16\% SDS-PAGE. Proteins were transferred to nitrocellulose membranes (Schleicher \& Schuell BioScience), and we performed immunodetection both for Abca1 using a polyclonal antibody, raised to a 24-mer peptide of the C-terminal region of mouse Abca1 conjugated to keyhole limpet hemocyanin, and for $\beta$-actin (Sigma-Aldrich), as a load control. Both Abca1 and $\beta$-actin were visualized using a chemiluminescent reagent (Pierce).

Membrane isolation and Western blot analysis of Abca1 in the liver. Mouse liver samples ( $\sim 300 \mathrm{mg}$ ) were homogenized with a Teflon homogenizer in isolation buffer (250 $\mathrm{mM}$ sucrose, $10 \mathrm{mM}$ triethanolamine $\mathrm{HCl}, \mathrm{pH}$ 7.6) containing protease inhibitors (0.1 mM PMSF in $95 \%$ ethanol, $10 \mu \mathrm{g} / \mathrm{ml}$ pepstatin, $10 \mu \mathrm{g} / \mathrm{ml}$ leupeptin, $10 \mu \mathrm{g} / \mathrm{ml}$ aprotinin) for a final concentration of $10 \%(\mathrm{wt} / \mathrm{vol})$. Homogenized tissues were centrifuged for $10 \mathrm{~min}$ utes at $3,300 \mathrm{~g}$ at $4^{\circ} \mathrm{C}$ to pellet cell debris and nuclei. The supernatant was recovered and centrifuged again for 20 minutes at $27,000 \mathrm{~g}$ at $4^{\circ} \mathrm{C}$, and the recovered pellet was washed 2 times by resuspension in the original volume of isolation buffer followed by centrifugation for 20 minutes at $27,000 \mathrm{~g}$ at $4{ }^{\circ} \mathrm{C}$. After the final resuspension of pellet in isolation buffer, protein concentration was determined using the Protein BCA Assay (Pierce).

Western blot analysis was conducted with $100 \mu \mathrm{g}$ of isolated liver membrane protein, as described above. In this experiment, Abca1 and $\beta$-actin signals were visualized using ${ }^{125}$ I-radiolabeled secondary antibody and quantified by PhosphorImager (GE Healthcare) analysis. Abca1 protein expression was normalized to $\beta$-actin for each sample.

Isolation and radioiodination of plasma HDL and apoA-I for turnover studies. Whole plasma from wild-type mice was fractionated on a Sepharose CL4B column $(2 \times 50 \mathrm{~cm}$; Amersham Biosciences $)$, and HDL elution position was monitored by enzymatic cholesterol assay (28). Individual fractions from the column were subjected to $4-30 \%$ nondenaturing gradient PAGE. Gels were stained and destained, and fractions that contained HDL particles with minimal albumin contamination were pooled. HDL particles were radiolabeled with $\left[{ }^{125} \mathrm{I}\right] \mathrm{TC}$ and subfractionated by size-exclusion chromatography using 3 Superdex 200 HR FPLC columns $(1 \times 30 \mathrm{~cm}$; Amersham Biosciences) in series (28). Individual fractions were analyzed by $4-30 \%$ nondenaturing gradient PAGE $\left(1,400 \mathrm{~V} / \mathrm{h}\right.$ at $\left.10^{\circ} \mathrm{C}\right)$, and the size of radiolabeled HDL particles was determined by PhosphorImager analysis. Individual fractions were pooled to give HDL particles of similar size. The specific activity of HDL was $545 \mathrm{cpm} / \mathrm{ng}$ protein, and trichloroacetic acid (TCA)-precipitable radioactivity was more than $99 \%$.

Lipid-free apoA-I was isolated from human plasma and radiolabeled with [125I]TC as described previously (28). The specific activity of the apoA-I tracer was $117 \mathrm{cpm} / \mathrm{ng}$ protein, and TCA-precipitable radioactivity was more than $99 \%$.

In vivo kinetic study. The in vivo kinetic study was performed with [ $\left.{ }^{125} \mathrm{I}\right] \mathrm{TC}-$ radiolabeled HDL particles or lipid-free apoA-I as previously described (28). Briefly, radiolabeled tracer $\left(4 \times 10^{5}\right.$ to $\left.8 \times 10^{5} \mathrm{cpm}\right)$ was injected into the jugular vein of anesthetized recipient mice, and blood samples were obtained by retro-orbital bleeding at 10 and 30 minutes and at 1, 2, 3, 5, 8, and 24 hours. Twenty-four hours after dose injection, animals were sacrificed, the vascular system was flushed with $15 \mathrm{ml}$ PBS, and the liver, intestine plus contents, and kidneys were harvested and digested with $1 \mathrm{~N} \mathrm{NaOH}$ overnight at $60^{\circ} \mathrm{C}$ prior to ${ }^{125} \mathrm{I}$ radiolabel quantification. FCR of plasma die-away curves was calculated using Simulation, Analysis, and Modeling software (SAAM II version 1.1.1; SAAM Institute) as described previously (28).

\section{Acknowledgments}

This work was supported by NIH grants HL49373 (to J.S. Parks), HL07115 (Cardiovascular Pathology Training grant; to J.M. Timmins), and HL42630 (to N. Maeda) and by grants from the Canadian Institutes of Health Research (to L.R. Brunham and M.R. Hayden), the Michael Smith Foundation for Health Research (to L.R. Brunham), The Saal van Zwanenberg foundation (to J.M. Coutinho), The Netherlands Heart Foundation (to J.M. Coutinho), and the Heart and Stroke Foundation of BC \& Yukon (to M.R. Hayden). M.R. Hayden holds a University Killam Professorship and is a Canada Research Chair in Human Genetics.

Received for publication November 16, 2004, and accepted in revised form February 15, 2005.

Address correspondence to: John S. Parks, Department of Pathology, Medical Center Boulevard, Wake Forest University School of Medicine, Winston-Salem, North Carolina 27157, USA. Phone: (336) 716-2145; Fax: (336) 716-6279; E-mail: jparks@wfubmc.edu.
1. Assmann, G., and Gotto, A.M., Jr. 2004. HDL cholesterol and protective factors in atherosclerosis. Circulation. 109(Suppl. 1):III8-III14.

2. Glomset, J.A. 1968. The plasma lecithin:cholesterol acyltransferase reaction. J. Lipid Res. 9:155-167.

3. Hamilton, R.L., Moorehouse, A., and Havel, R.J. 1991. Isolation and properties of nascent lipoproteins from highly purified rat hepatocytic Golgi fractions. J. Lipid Res. 32:529-543.

4. Hamilton, R.L., Guo, L.S., Felker, T.E., Chao, Y.S. and Havel, R.J. 1986. Nascent high density lipoproteins from liver perfusates of orotic acid-fed rats. J. Lipid Res. 27:967-978.

5. Oram, J.F., and Yokoyama, S. 1996. Apolipoproteinmediated removal of cellular cholesterol and phospholipids. J. Lipid Res. 37:2473-2491.
6. Francis, G.A., Knopp, R.H., and Oram, J.F. 1995. Defective removal of cellular cholesterol and phospholipids by apolipoprotein A-I in Tangier disease. J. Clin. Invest. 96:78-87.

7. Assman, G., von Eckardstein, A., and Brewer, H.B. Jr. 2001. Familial analphalipoproteinemia: Tangier disease. In The metabolic and molecular bases of inherited disease. C.R. Scriver et al., editors. McGraw-Hill. New York, New York, USA. 2937-2960.

8. Brooks-Wilson, A., et al. 1999. Mutations in ABC1 in Tangier disease and familial high-density lipoprotein deficiency. Nat. Genet. 22:336-345.

9. Bodzioch, M., et al. 1999. The gene encoding ATPbinding cassette transporter 1 is mutated in Tangier disease. Nat. Genet. 22:347-351.

10. Rust, S., et al. 1999. Tangier disease is caused by mutations in the gene encoding ATP-binding cassette transporter 1. Nat. Genet. 22:352-355.

11. Wellington, C.L., et al. 2003. Alterations of plasma lipids in mice via adenoviral-mediated hepatic overexpression of human ABCA1. J. Lipid Res. 44:1470-1480.

12. Basso, F., et al. 2003. Role of the hepatic ABCA1 transporter in modulating intrahepatic cholesterol and plasma HDL cholesterol concentrations. J. Lipid Res. 44:296-302.

13. Vaisman, B.L., et al. 2001. ABCA1 overexpression leads to hyperalphalipoproteinemia and increased biliary cholesterol excretion in transgenic mice. J. Clin. Invest. 108:303-309. doi:10.1172/JCI200112517.

14. Haghpassand, M., Bourassa, P.A., Francone, O.L., and Aiello, R.J. 2001. Monocyte/macrophage 
expression of $\mathrm{ABCA} 1$ has minimal contribution to plasma HDL levels. J. Clin. Invest. 108:1315-1320. doi:10.1172/JCI200112810.

15. Wu, A.L., and Windmueller, H.G. 1979. Relative contributions by liver and intestine to individual plasma apolipoproteins in the rat. J. Biol. Chem. 254:7316-7322.

16. Postic, C., et al. 1999. Dual roles for glucokinase in glucose homeostasis as determined by liver and pancreatic beta cell-specific gene knock-outs using Cre recombinase. J. Biol. Chem. 274:305-315.

17. Christiansen-Weber, T.A., et al. 2000. Functional loss of ABCA1 in mice causes severe placental malformation, aberrant lipid distribution, and kidney glomerulonephritis as well as high-density lipoprotein cholesterol deficiency. Am. J. Pathol. 157:1017-1029.

18. McNeish, J., et al. 2000. High density lipoprotein deficiency and foam cell accumulation in mice with targeted disruption of ATP-binding cassette transporter-1. Proc. Natl. Acad. Sci. U. S. A. 97:4245-4250.

19. Selva, D.M., et al. 2004. The ATP-binding cassette transporter 1 mediates lipid efflux from Sertoli cells and influences male fertility. J. Lipid Res. 45:1040-1050.

20. Schaefer, E.J., et al 1978. Metabolism of high-density lipoprotein apolipoproteins in Tangier disease. N. Engl. J. Med. 299:905-910.

21. Wang, N., Silver, D.L., Costet, P., and Tall, A.R 2000. Specific binding of ApoA-I, enhanced cholesterol efflux, and altered plasma membrane morphology in cells expressing ABC1. J. Biol. Chem. 275:33053-33058

22. Schaefer, E.J., et al. 1981. Metabolism of high density lipoprotein subfractions and constituents in Tangier disease following the infusion of high density lipoproteins. J. Lipid Res. 22:217-228.

23. Attie, A.D., et al. 2002. Identification and functional analysis of a naturally occurring E89K mutation in the ABCA1 gene of the WHAM chicken. J. Lipid Res. 43:1610-1617.

24. Schreyer, S.A., Hart, L.K., and Attie, A.D. 1994 Hypercatabolism of lipoprotein-free apolipoprotein A-I in HDL-deficient mutant chickens. Arterioscler. Thromb. Vasc. Biol. 14:2053-2059.

25. Pittman, R.C., et al. 1983. A radioiodinated, intracellularly trapped ligand for determining the sites of plasma protein degradation in vivo. Biochem. J. 212:791-800.

26. Francone, O.L., Subbaiah, P.V., Van Tol, A., Royer, L., and Haghpassand, M. 2003. Abnormal phospholipid composition impairs HDL biogenesis and maturation in mice lacking Abca1. Biochemistry. 42:8569-8578.

27. Huggins, K.W., et al. 2000. Determination of the tissue sites responsible for the catabolism of large high density lipoprotein in the African green monkey. J. Lipid Res. 41:384-394.

28. Lee, J.Y., et al 2004. Prebeta high density lipoprotein has two metabolic fates in human apolipoprotein A-I transgenic mice. J. Lipid Res. 45:716-728.

29. Glass, C., Pittman, R.C., Civen, M., and Steinberg, D. 1985. Uptake of high-density lipoprotein-associated apoprotein A-I and cholesterol esters by 16 tissues of the rat in vivo and by adrenal cells and hepatocytes in vitro. J. Biol. Chem. 260:744-750.

30. Glass, C.K., Pittman, R.C., Keller, G.A., and Steinberg, D. 1983. Tissue sites of degradation of apoprotein A-I in the rat. J. Biol. Chem. 258:7161-7167.

31. Singaraja, R.R., Brunham, L.R., Visscher, H., Kastelein, J.J.P., and Hayden, M.R. 2003. Efflux and atherosclerosis: the clinical and biochemical impact of variations in the ABCA1 gene. Arterioscler. Thromb. Vasc. Biol. 23:1322-1332.

32. Wellington, C.L., et al. 2002. ABCA1 mRNA and protein distribution patterns predict multiple different roles and levels of regulation. Lab. Invest. 82:273-283.

33. Chisholm, J.W., Burleson, E.R., Shelness, G.S., and Parks, J.S. 2002. ApoA-I secretion from HepG2 cells: evidence for the secretion of both lipid-poor apoA-I and intracellularly assembled nascent HDL. J. Lipid Res. 43:36-44.

34. Kiss, R.S., et al. 2003. The lipidation by hepatocytes of human apolipoprotein A-I occurs by both ABCA1-dependent and -independent pathways. J. Biol. Chem. 278:10119-10127.

35. Rothblat, G.H., et al. 1999. Cell cholesterol efflux: integration of old and new observations provides new insights. J. Lipid Res. 40:781-796.

36. Wang, N., Lan, D., Chen, W., Matsuura, F., and Tall, A.R. 2004. ATP-binding cassette transporters G1 and G4 mediate cellular cholesterol efflux to highdensity lipoproteins. Proc. Natl. Acad. Sci. U. S. A. 101:9774-9779.

37. Van Eck, M., et al. 2002. Leukocyte ABCA1 controls susceptibility to atherosclerosis and macrophage recruitment into tissues. Proc. Natl. Acad. Sci. U. S. A. 99:6298-6303

38. Aiello, R.J., et al. 2002. Increased atherosclerosis in hyperlipidemic mice with inactivation of ABCA1 in macrophages. Arterioscler. Thromb. Vasc. Biol. 22:630-637.
39. Assmann, G., and Smootz, E. 1978. High density lipoprotein infusion and partial plasma exchange in Tangier disease. Eur. J. Clin. Invest. 8:131-135.

40. Denis, M., et al. 2004. Molecular and cellular physiology of apolipoprotein A-I lipidation by the ATPbinding cassette transporter A1 (ABCA1). J. Biol. Chem. 279:7384-7394.

41. Furbee, J.W., Jr., Francone, O.L., and Parks, J.S. 2001. Alteration of plasma HDL cholesteryl ester composition with transgenic expression of a point mutation (E149A) of human lecithin:cholesterol acyltransferase (LCAT). J. Lipid Res. 42:1626-1635.

42. Livak, K.J., and Schmittgen, T.D. 2001. Analysis of relative gene expression data using real-time quantitative PCR and the 2(-Delta Delta C(T)) Method. Methods. 25:402-408.

43. Furbee, J.W., Jr., Francone, O.L., and Parks, J.S. 2002. In vivo contribution of lecithin:cholesterol acyltransferase (LCAT) to apolipoprotein B lipoprotein cholesteryl esters in low density lipoprotein receptor and apolipoprotein $\mathrm{E}$ knockout mice. J. Lipid Res. 43:428-437.

44. Koritnik, D.L., and Rudel, L.L. 1983. Measurement of apolipoprotein A-I concentration in nonhuman primate serum by enzyme-linked immunosorbent assay (ELISA). J. Lipid Res. 24:1639-1645.

45. Parks, J.S., Gebre, A.K., and Furbee, J.W., Jr. 1998. Lecithin-cholesterol acyltransferase. Assay of cholesterol esterification and phospholipase A2 activities. In Methods in molecular biology. M. Doolittle and K. Reue, editors. Humana Press. Totowa, New Jersey, USA. 123-131.

46. Wilcox, R.W., Thuren, T., Sisson, P., Kucera, G.L., and Waite, M. 1991. Hydrolysis of neutral lipid substrates by rat hepatic lipase. Lipids. 26:283-288.

47. Furbee, J.W., Jr., Sawyer, J.K., and Parks, J.S. 2002. Lecithin:cholesterol acyltransferase deficiency increases atherosclerosis in the low density lipoprotein receptor and apolipoprotein E knockout mice. J. Biol. Chem. 277:3511-3519.

48. Twisk, J., et al. 2000. The role of the LDL receptor in apolipoprotein B secretion. J. Clin. Invest. 105:521-532.

49. Wellington, C.L., et al. 2002. Truncation mutations in ABCA1 suppress normal upregulation of full-length ABCA1 by 9-cis-retinoic acid and 22-Rhydroxycholesterol. J. Lipid Res. 43:1939-1949.

50. See, R.H., et al. 2002. Protein kinase A site-specific phosphorylation regulates ATP-binding cassette A1 (ABCA1)-mediated phospholipid efflux. J. Biol. Chem. 277:41835-41842. 